Fourth International Conference on Sustainable Construction Materials and Technologies http://www.claisse.info/Proceedings.htm

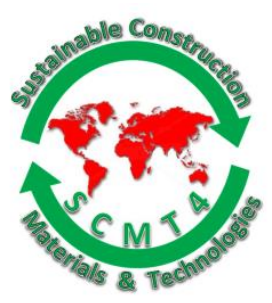

SCMT4

Las Vegas, USA, August 7-11, 2016

\title{
Thinking Smart: Residential Green Retrofit, India
}

\author{
Manisha G Das ${ }^{1 \mathrm{a}}$, and Debashish Das ${ }^{1 \mathrm{~b}}$ \\ ${ }^{1}$ Sustainable Urban Metasystems; SUM@ark, a GREEN think tank - 177, Gulmohar Enclave, \\ New Delhi - 110049. ${ }^{1 a}$ Email: <manisha.gdas@ark-india.co.in>, ${ }^{1 b}$ Professor; ${ }^{1 b}$ Email: \\ <debashish.das@ark-india.co.in>.
}

\begin{abstract}
This paper explores ways and means of incentivizing and implementing GREEN building retrofits for Residential sector, in the Tier I \& II cities of India. The central government has introduced several initiatives that find specific mention in India's INDCs as instruments for combating climate change. Including both, voluntary GREEN rating schemes and mandates for ENERGY Conservation. Significant fiscal allocations from the government and multilateral funds have been earmarked. However, there remains a disconnect between intent and reality in terms of implement-ability, willingness and a certain sluggishness in the system. While an overwhelming mandatory regime will be debilitating for a developing economy and be met with great resistance, a combination of incentivization and an enabling legal-fiscal environment targeting low hanging fruits initially and with progressively increasing stringency, could achieve broader acceptability with far reaching results. This paper further builds on the premise that green or sustainable design, cannot be viewed as just a building mandate or bye law but rather an economically sustainable lifestyle choice, and hence to incentivize this drive, will develop it as a social and cultural movement.
\end{abstract}

\section{INTRODUCTION}

An average Indian lives within a complex system of competing beliefs, philosophies and values, where given the average GDP and the vast disparity in our economic classes, financial considerations is the only true north in almost all decision-making exercises. This is in spite of an ingrained respect for nature intrinsic to our socio-religious value systems. To bring about a convincing change in how we manage our energy economy as a nation, it is necessary to leverage the potential of acceptable change in the homes of our billions. Awareness about, and implementation of green designs can be achieved and expected to gain momentum through the proactive participation of these billion stakeholders, living in cities and towns.

India has been urbanising at a rapid rate. A 2010 McKinsey Report on urbanisation, states that by 2030, 590 million will live in cities as against the 377 million of the total population of 1210 million under the 2011 census of India. (MGI, 2010). Present figures of 9, 33 and 5000 for Tier I, II \& III cities in India are expected to reach 13, 55 and 6000 respectively by the year 2030. Built stock (as per 2011 census figures) stood at 78 million housing units for around 78 million urban households. Pretty much at parity? It still 
fails to meet housing need as:

... Much of the existing stock is dilapidated and hardly fit for habitation;

... Multiple families share highly congested households;

... Substantial stock is unoccupied

Construction boom in the 2000s combined with stable economy and lower interest rate on other financial instruments ignited a hitherto less popular inclination to "invest" in real estate; artificially pushing up prices yet keeping demand constant as the property bought largely as investment instruments is not necessarily offered up on rent or lease owing to rampant land sharks and goons operating in the real-estate market and an antiquated Rent Control Act, which empowers the lessee above the lesser making an insecure lease environment. With two third of India's expected built stock yet to break ground, this incredible rise in expected urban population is expected to spike the housing demand by 2030. As per KPMG report, a large majority of this new built stock needs to be in the affordable segment. According to the recently conducted study by KPMG, urban centers in the state of Maharashtra alone would need 50 million new homes by 2022; amounting to a 50\% increase over current levels. $70 \%$ of this new capacity needs to be affordable. (KPMG, n.d.)

Talking only in terms of Energy, it begs the question - Are we equipped to meet the power demands of these new additions? Even if we do, can it be affordable?

Urban Energy consumption for the residential sector contributes to $22 \%$ share of the entire electricity consumption in India, as against a $9 \%$ by the commercial sector. (MoSPI, 2015). The same report states that the total potential for renewable Energy in India is to the tune of $\sim 148$ Gigawatt, of which $70 \%$ is wind, $13 \%$ being small hydro, $12 \%$ being Biomass and $2 \%$ waste to energy. Gujarat, Karnataka, Andhra Pradesh, Tamil Nadu, Maharashtra, make up for $67 \%$ of the potential owing largely to suitable conditions for wind power. The total electricity consumption in India over the 2013-14 FY, stands at 882,592 Gigawatt hour.

Much like filling a leaky bucket, the clean energy drive in India, is ineffective without energy conservation measures addressing both existing and proposed built stock in the Urban India. And then again, energy conservation alone does not make for a wholesome approach to sustainability. From voluntary green building ratings like GRIHA, IGBC and BEE star rating for buildings, that have found some but limited takers in the building industry, India is gradually but surely moving towards mandates like the Energy Conservation Building Code, revision to the National Building Code 2005, and adoption of minimum 3 star GRIHA rating for all new central government constructions.

While most all these are being mandated for the Commercial sector, the Residential sector is yet to see set rules or mandates. The 2014 design guidelines for multi storey residential buildings for Hot-Dry and Composite climate developed by BEE (BEE, 2014) are little known and have no supporting implementation or awareness strategy. Another voluntary rating system for homes, new constructions is SVA GRIHA, a self-appraisal, voluntary rating by GRIHA for homes has not many takers, and suffers a similar fate. Same is the case for IGBC's GREEN home rating systems. Developers are hesitant to go in for ratings for larger projects with the worry that 'GREEN' guidelines add clauses to lease and home owners' contracts which effect saleability and also hike up initial capital expenditure, with no parallel assurance of profits or increase in saleability.

A decentralised drive, like mandate and implementation of ECBC, many State governments' claims to nudge the building industry towards adopting Green and sustainable measures fails under close scrutiny and has deservedly come under severe criticism. Some state governments have initiated a move to grant as high as $10 \%$ extra FAR /development rights to real estate developers adopting green certifications. Unfortunately, the program is not backed by informed enquiry and lacks transparency. Concerned 
departments also markedly lack the capacity to undertake examination or monitoring of the developers' execution.

Under the circumstances, few issues emerge in sharp focus:

- The urban residential concentration in India is about to increase manifold

- The high percentage attributed to residential households in the energy demand mix cannot be met by renewables only.

- Residential solutions need to be viewed in larger sustainability matrix involving whole-building green designs

- Solutions need to be sustainable as well as affordable

- Solutions need to be participatory, and self-owned

- The governments at central and state levels are ill-equipped to address the situation by themselves and need to engage with the private and retail sector, and the building Industry.

\section{The proposal}

First let's consider why RESIDENTIAL: A 'Home-owners' policy. The Rent Control Act, 1958, both regulates rent and recognises dwelling rights of the lessee in case of a longer duration of residence in the same premises, which in turn, discourages home owners from renting out accommodation for longer periods of time, leading to a general practice of 11 month lease/rent contracts which are revised each year. Lessees, as a safety measure, are encouraged to vacate every 1-2 years by the owners. Looking for newer accommodation and settling in, every 12 months, can be majorly disruptive to daily schedules and lives. Thus there comes a preference to be home owners, rather than to rent accommodation, where affordable. This is especially so in case of HIG (High Income Group) and MIG (Middle Income Group) sectors. If we assess the numbers, as against today's 22 million urban households, 91 million are expected to be middle class by 2030. With this projected increase in affordability numbers, policies charted towards home owners might well offer answers to the crisis.

A Tangible measure - Energy Performance Index \& avg. household value. EPI or an Energy Performance Index measures energy consumption of a built up space in terms of energy demand (in kilowatt-hours) per unit area (in square meters) per year. Enhancement in energy performance (i.e. reduced EPI) is a good means for apple to apple comparison within specific building categories and helps rationalise standards of performance across the varied range of climatic conditions within the Indian subcontinent.

Average EPI for residences: HIG - 80-90kWhr/sqm/year; MIG - 48kWhr/sqm/year (BEE, 2014)

has to be read in conjunction with potential increase of $10-40 \mathrm{kWh} / \mathrm{sqm} / \mathrm{year}$ for every additional Air conditioning unit. (GBPN, 2015). For top floors with heat gain from non-insulated roofs (as is the norm in India) this requirement goes up by another $10-15 \%$.

The major consumer of energy in the residence : Heating, Ventilation \& Cooling Loads. In MIG and above, HVAC loads stand at a major 50-75\% share of the total energy usage per household (The World Bank, 2008). Cooling loads are expected to continue being the lion's share of the residential energy requirement in India in an ever deepening cycle with global warming. In case of Grid failure, energy is fed by back-up diesel generators, which add to emissions. 
Figure 1. Average operating per-unit power consumption for household appliances (The World Bank, 2008)

\begin{tabular}{|c|c|c|c|c|c|c|c|}
\hline & & 2006 & 2011 & 2016 & 2021 & 2026 & 2031 \\
\hline \multicolumn{8}{|l|}{ General } \\
\hline Lighting & $\mathrm{W} / \mathrm{hr}$ & 37 & 39 & 38 & 38 & 39 & 38 \\
\hline \multicolumn{8}{|l|}{ Entertainment } \\
\hline Radio & $\mathrm{W} / \mathrm{hr}$ & 11 & 11 & 11 & 11 & 11 & 11 \\
\hline CD Player & $\mathrm{W} / \mathrm{hr}$ & 35 & 35 & 35 & 35 & 35 & 35 \\
\hline TV & $\mathrm{W} / \mathrm{hr}$ & 77 & 92 & 113 & 127 & 135 & 139 \\
\hline OVD / VCR & $\mathrm{W} / \mathrm{hr}$ & 40 & 35 & 32 & 31 & 30 & 30 \\
\hline Computer & $\mathrm{W} / \mathrm{hr}$ & 116 & 71 & 64 & 64 & 64 & 64 \\
\hline \multicolumn{8}{|l|}{ White Appliances } \\
\hline Washing machines & Wh/load & 101 & 112 & 130 & 149 & 163 & 174 \\
\hline Refrigerator & kWh/Unit & 705 & 568 & 473 & 431 & 417 & 418 \\
\hline Electric Oven & $\mathrm{W} / \mathrm{hr}$ & 960 & 1,088 & 1,193 & 1,248 & 1,271 & 1,279 \\
\hline Toaster & W/hr & 800 & 1,031 & 1,182 & 1,246 & 1,270 & 1,278 \\
\hline Microwave & $\mathrm{W} / \mathrm{hr}$ & 1,080 & 1,080 & 1,080 & 1,080 & 1,080 & 1,080 \\
\hline \multicolumn{8}{|l|}{ Heating / Cooling } \\
\hline Electric Water Heater & kWh/Unit & 609 & 591 & 575 & 566 & 562 & 561 \\
\hline Fans & W/hr & 39 & 38 & 37 & 37 & 37 & 36 \\
\hline Air cooler & W/hr & 250 & 241 & 235 & 232 & 231 & 230 \\
\hline Air-conditioning & W/hr & 1.973 & 1.883 & 1.834 & 1.817 & 1.811 & 1.809 \\
\hline
\end{tabular}

Unlike offices, where internal heat gains like equipment and personnel add to cooling loads significantly, cooling loads for residences are largely due to the solar heat gain through the built envelope (roof, walls, windows, doors, and air leakage) (BEE, 2014).

Electricity for space cooling varies from $33 \%$ to $65 \%$ of the total billed units in a given 2-3 bedroom multi storey unit in Delhi, and it more than doubles when shifting from desert coolers to refrigerant based air conditioners. (BEE, 2014) Another aspect being that at an average 16\% of the total energy requirement goes behind common area requirements for multi storied residential buildings, of which $62 \%$ goes behind operation of lifts, $21 \%$ behind common area lighting and $17 \%$ behind water pumping. (BEE, 2014). This water pumping energy requirement for dessert coolers also needs to be considered when calculating cooling loads wherever evaporative cooling ( dessert coolers) can be considered.

\section{So why not Solar: Solar irradiation in India}

Exploring how, if at all, we can meet the energy requirements for these units through on-site generated clean energy, we find that though India enjoys considerable irradiation levels and degree days, much of it is concentrated only along the Western and Southern belts. The rest of the country sees irradiation in the range of 4-7 kWh/sqm/day (Annexure I, Solar Irradiation Map of India), which doesn't necessarily provide for a highly efficient system.

At ballpark figures, every $1 \mathrm{kWp}$ installation costs in the range of INR 80,000 to 120,000 and requires more or less a roof area of around 10sqm. For an average roof size of even low rise (say G+2) units, given a standard MIG unit size of $100 \mathrm{sqm}$, the roof area available per household is around $30 \mathrm{sqm}$. This 
amounts to a maximum of $2.5 \mathrm{kWp}$ installation, at an initial capital expenditure of around INR 0.3 million, which might well be affordable, but at a $15 \mathrm{kWh}$ per day requirement for an MIG unit (based on average EPI), a 5 hr sun-day for about 250 degree days, it is just not sufficient. This paper explores the various possibilities for retrofitting the existing built stock for better performance.

\section{Grading the RETROFIT of existing Built Stock}

For retrofit of existing residences we at SUM@ARK are exploring policy level approaches, which can be considered for the sake of standardization but vary largely based on the level of intervention required and prioritization based on maximum benefit in terms of efficiency with the least level of disruption, referred to here as deep or surface.

By surface we refer to a first line of defense, the low-hanging fruit involving minimal intervention or disruption of the existing built fabric, and inhabitant's lives. The suggestions here are neither a comprehensive list of measures, nor a detailed review which would necessarily have to be case specific, but rather come from an amalgamation of prevalent codes, Green building rating systems, and guidelines from various governmental agencies like Bureau of Energy Efficiency and our experience with green buildings over time.

\section{Table 1. Proposed Layers for Dwelling Retrofit}

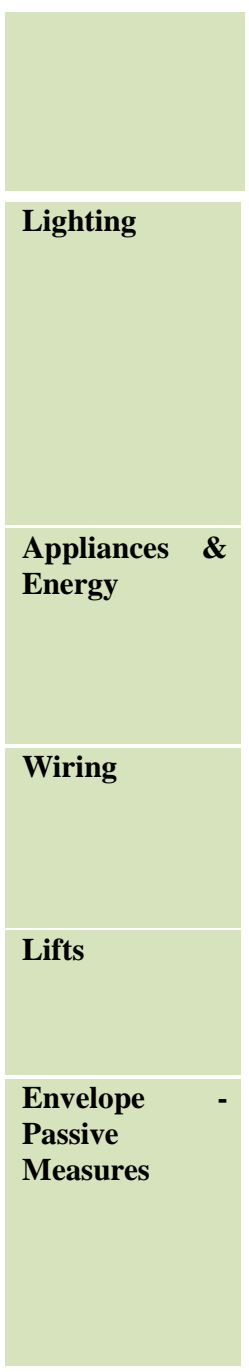

\section{SURFACE LAYER -}

(Nill to Minimal Disturbance to the Dwelling unit)

Replace Lamps, both common area and internal household, with LED.

Where Possible replace with solar lanters, gradually.

Upgrading appliances to star rated energy efficient ones, especially for heating/cooling, , refrigerators, microwaves, ovens, etc which are the main players in the domestic electricity bill.

Installing capacitors for the house wiring to discourage $T \& D$ losses within the premises.

Lifts, say for multi-storey apartment housing to be tuned for maximum efficiency (BEE, 2014)

1. High Solar reflective Index paints/tiles for Roof.

2. Self Shading texturs/ cladding for Walls

3. Planting trees/ greening / shade incorporation for South and west walls.

\section{LIGHT GREEN LAYER-}

(A base level of cost \& interference to the unit, can be achieved without major disruption to the unit and inhabitants)

\section{Redesigning and replacing Luminaries and system of controllers, sensors and dampers for efficient lighting, in accordance with the code subscribed Lux Levels. \\ 2.Solar Lanterns and lighting systems.}

Installation of Renewable energy to meet upto $50 \%$ unit's energy requirements, like Solar Water heaters \& Solar Cookers.

Change old Wiring and ensure minimal T\&D losses within the distribution cicuit

Lift motors, especially for older multi-storey apartment housing replaced for maximum efficiency (BEE, 2014)

1. Roof deck shading, landscaping and or Insulation, to minimize solar heat gain and cooling/heating losses (as applicable)

2. Wall Insulation incorporation to achieve minimal Solar Heat gain and heating/cooling losses

\section{DEEP GREEN LAYER-}

(A complete re-haul towards net-zero neutrality of the Dwelling unit common areas and neighborhood)

\section{Redesigning the internal and} external lighting systems to be co-ordinated with day-lighting in accordance with the code subscribed Lux Levels.

2. District/ neighbourhood level measures like occupant sensor lighting for streets, daylight sensors, solar lighting, etc.

\section{Whole building Design, retrofit,} install and augment RE to meet Net-Zero with respect to individual dwelling and common area Energy Requirements.

Align to whole building design and Redesign Distribution \& electrical systems to ensure minimal losses, employing sensors, monitors, etc.

Switching to lo-energy and Hydraulic systems where possible.

1. Roof Deck, Wall Envelope and Retrofit for zero heat gain / losses as per the Climate.

2. Energy efficient envelope integrated cooling/ heating systems like chilled beams, water cooled walls, trombe 
SURFACE LAYER -

(Nill to Minimal Disturbance to the Dwelling unit)

\section{Damage repairs}

Fenestration Heat Gain

Fenestration Day Lighting

\section{Energy \\ Efficient \\ Cooling}

\section{Water}

Pumpimg and distribution Management

Solid Waste Management
Air Quality checks and records. Low VOC paints and finishing compounds.

Ensure air tightness of all heated / cooled spaces aginst leakage. Revamp the trims around all fenestrations like windows, glazing, doors, etc.

Designing and changing internal layouts and colour schemes for furniture, blinds, linen, cabinets, floors, walls and ceilings deeper spaces, to ensure enough reflected light and therefore appropriate Lux levels without artificial lighting during sun-lit hours.

1. Optimizing Natural ventilation

2. Addition and or replacement and use of evaporative cooling systems wherever applicable as against refrigerant based.

3. Rehauling of existing systems with motors, sensors and corrective measures like higher threshold temperature settings, etc.

1. Switching to lo-flow fixtures

2. RO waste water, etc to be redirected for kitchen garden irrigation or flushing

3. Encouragement for Bucket Bath, and water wastage reduction.

1. Regular cleaning and maintenance of water pumping system, the distribution and drainage systems to ensure against blockages and leakages.

2. Re-hauling common area and individual dwelling units' pumps for maximum efficiency.

3. Scheduled and timely operation of domestic supply pumps in Daily scheduling to avoid unnecessary and repeated operation.

1. Recycle, Reduce, Reuse being the key, waste segregation, should be
LIGHT GREEN LAYER-

(A base level of cost \& interference to the unit, can be achieved without major disruption to the unit and inhabitants)

Mold and waterproofing failure detection and repairs.

1. Lo-Energy films for glazing to reduce Heat gain.

2. Awnings and shading device installations for external openings.

1. Design \& Installation of passive day-light penetration and diffusion devices like Light shelves.

2. Redesigning Landscape and external measures and facades to ensure optimum indoor day lighting minimizing direct Solar heat gain.

1. Centralized Radiant heating /cooling systems like chilled panel false ceiling, underfloor cooling, chilled beam, etc.

2. Enhancing and incorporating tradition techniques of cross ventilation, shading, convection currents, solar chimneys, etc.

1. Replacement of plumbing faucets and fixtures with low flow fixtures

2. rainwater harvesting where applicable and possible

3. Re-design for gravity based distribution rather than pressurized jockey pump based for multi-storeys and dwelling units.

1. Rehauling / Replacement of pumps and motors ensuring they run at $75 \%$ efficiency.

2. Calibration and correction of piping systems in case required to ensure energy efficient pumping and distribution, where valid.

1.District level solid waste management, including
DEEP GREEN LAYER-

(A complete re-haul towards net-zero neutrality of the Dwelling unit common areas and neighborhood)

walls, etc as applicable

Structural Rehabilitation/

redesign if required.

Lower SHGC window design and Replacement

1. High VLT, Lo-SHGC glass

2. Skylights, clerestories, Openings added/removed to achieve optimum levels, reducing glare.

3. District/neighbourhod level landscape and colour strategy to analyse shading and day light specific to each inhabited space within the neighbourhood.

\section{District Cooling / Heating}

2. Solar powered Cooling system

3. Geo-Thermal Cooling systems

1. localised sewage treatment plant at plot or neighbourood level

2. Water recycling unit for grey water, and redoing of the plumbing and drainage system to use the recycled grey water for flushing, irrigation and other such activities.

1. Reviewing and designing and upgrading (if required) the water supply, drainage and pumping system to work in tandem and to their maximum efficiency.

2. Softener and iron filtration system installation to further safeguard the system against rusting, iron deposit and scaling.

3. rainwater management to manage run-off

4. groundwater recharge

1. District Level Energy from Waste. 


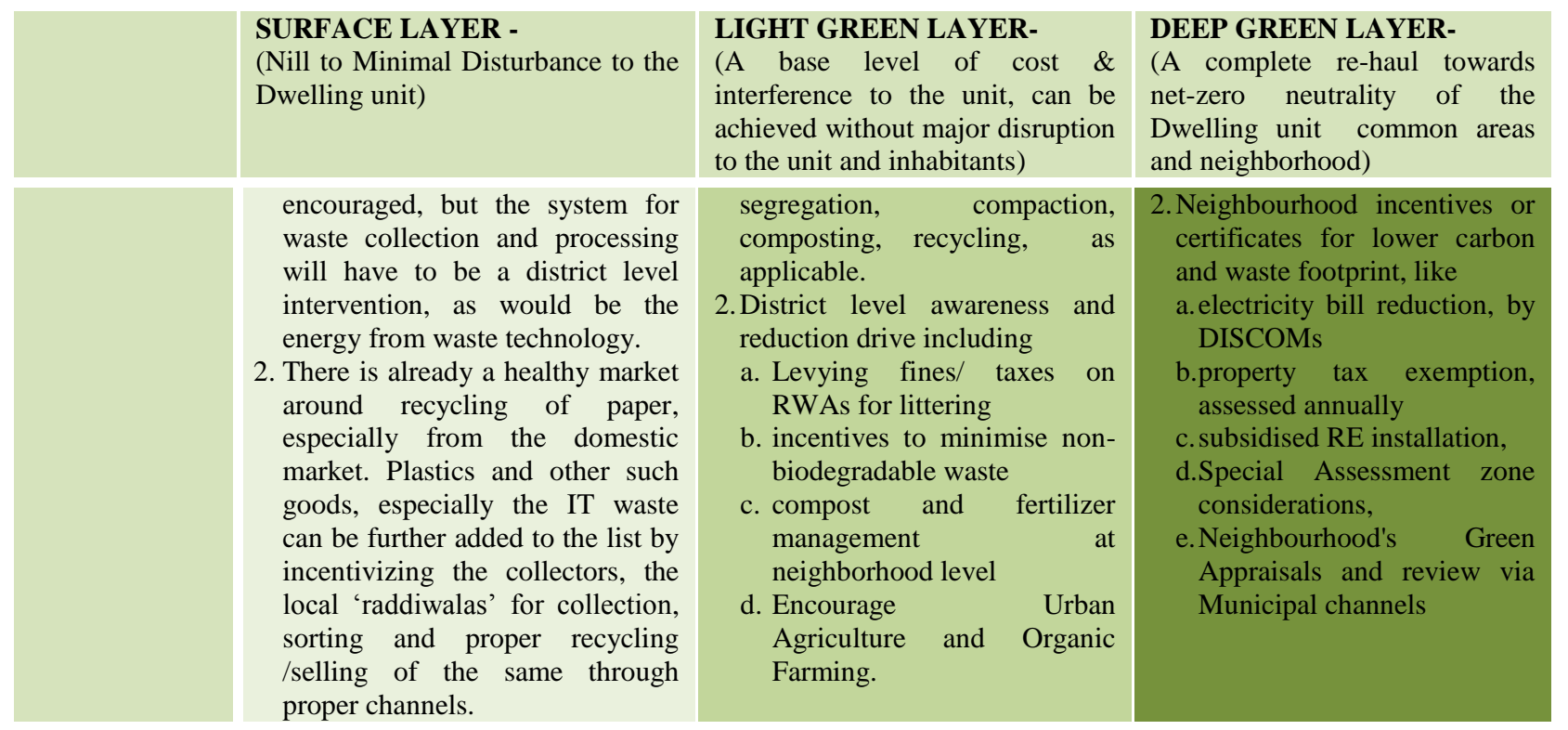

\section{District Level Measures}

District or neighborhood level Measures and support systems are necessary to support the above interventions. The possibility is further increased in view of the increasing number of gated communities and neighborhoods, both in apartment housing and plotted developments (Condominiums). These neighborhoods mostly have independent Resident Welfare Associations (RWAs) which can be mobilized and incentivized for collective effort. Some more possible measures other than the ones covered above are as follows

1. District level clean energy generation, from waste (Bio-Gas solutions), Solar, etc.

2. District heating / cooling

3. Ground water recharge and Rain water management

4. Top soil conservation and compost management
a. Tree \& Native species planting, care and maintenace.
b. Deep-root soil and compaction design for road side planting.
c. Earth berming and other mechanisms decreasing run-off, soil erosion
d. Preferred parking for electrical vehicles and Bicycles
e. Reed-bed Sewage treatment plants.

5. Grey water recycling and reuse for irrigation

6. Energy efficient measures deployed for street and common area Lighting, Lifts, water pumping systems, common facilities. Renewable energy for the same where possible and RE banks above public areas, like streets and canals, case in point Sabarmati canal, Gujarat.

7. Minimise usage of Diesel Generators - Investment in Electrical grass mowers, Renewable Energy, Battery backup for emergency lighting, etc.

\section{Incentivising Energy Efficiency - Case study}

"Incentivisation is the term used to align the motivations of the client with the supplier and vice-versa, so that the supplier is stimulated to improve their performance so as to benefit the client. This is usually in return for enhanced reward for the supplier, whether this is of a financial nature or takes the form of some other benefit to the supplier." (CIPS, n.d.) Incentivisation must be seen by both parties to be win-win, and there should be no hidden agendas. (CIPS, n.d.)

The first layer of such and similar interventions can be aimed at immediate energy efficiency and water 
efficiency. A good example can be found in the scheme launched sometime back by EESL. Ministry of Power, back in 2009- 10 set up Energy Efficiency Services Limited (EESL), a Joint Venture of NTPC Limited, PFC, REC and POWERGRID, etc. to facilitate implementation of energy efficiency projects. Activities under the ESCO model involved replacing CFLs with LED in residences, by distribution of one LED bulb each with every domestic electricity bill at a high subsidy. This was readily done and the subsidy borne by the distribution company itself, because the model was worked in a manner where firstly the procurement of the LEDs was done in bulk, ensuring substantial cost reduction due to manufacture discounts. Secondly the shift to LED promised a peak hour reduction in electricity usage which helped make up for any supply shortage and some could be re-utilised for other purposes. Such eforts can be accounted to less than tap 5\% of the potential market for energy efficiency and related products. (EESL, Energy Efficiency Services Limited, n.d.)

The reason that energy efficiency models don't work without bodies like the EESL or State owned distribution companies, is because the interests of the privately owned distribution companies, do not align with reducing the average bill. Each domestic bill, like say the Calcutta Electricity Supply Corporation (CESC), is subsidised upto 300 units, and doubly so below 150 units of monthly consumption. Lower the usage, higher the subsidy. In a nutshell, with higher efficiency in homes, the distribution company suffers losses in lieu of subsidy to be given. In absence of shortage in many states, the regulations and subsidies will have to be brought in line to align with the interests of these distribution companies and building industry's drive towards energy efficiency.

District measures, incentivizing, and layered retrofit or green appraisal approach leads to multiple players within the system, increasing complexity. It however, encourages a participatory approach from the stakeholders, where true effectiveness can be achieved when the citizens become the suppliers as well as the customers. The government plays only a modal role. This piecemeal approach is advisable as it can also be customized to various regions climes and situations, much the need for the vast sub-continent and is a crucial factors in self-ownership, critical to the maintenance, continuance and development of these programs.

It needs to be further supported by green appraisals; individual and district certification; earmarking of zones, districts \& neighborhoods for benefits like district measures, GREEN property appraisals, ease of mortgage and lower interest rates. Retail Financial instruments like soft loans to individual property owners for GREEN retrofits. A system, if developed on lines parallel to zoning laws like, TDRs (Transfer of Development Rights) or tradable instruments like Renewable Energy Certificates, RECs prevalent in India, or even the recently introduced net metering, could offer tangible commercial benefits to Individual house owners, RWAs, districts or Wards. Energy Efficiency and Clean energy generation certificates awarded to these RWAs or Districts, could further become tradable instruments across sectors.

\section{The Property Assessed Clean Energy (PACE) Program}

The solution for California's homes (Hofmeister, 2014, p. Blog) ${ }^{1}$ with PACE's program for funding clean energy retrofits for homes with no initial investment, could well be replicated here within the Indian city context. The challenge remains to make it into a viable proposal suited to our local governance, policy and revenue system.

The Property Assessed Clean Energy (PACE) program (Governor, 2014), in California allows home owners to fund the installation of lo-low fixtures, solar panels, Insulation, energy efficient lighting and other GREEN measures with no initial down payment and can pay it off over the years through their annual property tax payments. If a homeowner sells his or her property, the PACE assessment and property improvements transfer to the new owner.

\footnotetext{
${ }^{1}$ http://blogs.edf.org/energyexchange/2014/03/19/pace-financing-for-californias-clean-energy-future-part-1-expanding-the-residential-market/
} 
It also allows the local governments to fund these residential retrofits by selling public bonds for clean energy and water efficiency. Prior to the PACE law, as per the Berkley's CLEE ${ }^{2}$ comments on FHFA's proposed solution to the earlier stay on the PACE in 2010 due to risk to the first mortgage lender, special assessments (as part of the special assessment districts) have been applied to finance a wide array of public improvements ranging from sidewalks, curbs, sewers, seismic upgrades on private property, septic upgrades, business improvements, security improvements, and street lights. To ensure returns state statutory frameworks frequently structure assessment districts to have priority lien status over pre-existing mortgages.

DOE's initial text of the ACT for PACE in $2011^{3}$ states the duration of PACE programs to no more than twenty years or the weighted average expected useful life of the PACE improvement or improvements, whichever is shorter, under the TERMS of FINANCING. Further the Berkley's CLEE comments state that the mortgage default risks have been found to be lower for homeowners who receive PACE funding for qualified improvements, and that homes with energy efficiency upgrades sell for a premium over homes without such improvements.

CLEE comments also state that the PACE actually decreases risk to the financing / insuring agency as it reduces the Net cost to the home-owner. Also PACE program provides similar community level benefits like street lighting, sewerage, water supply, by reduced energy consumption, lower potable water demand, Reduce air pollution by adoption of GREEN energy, reduce greenhouse gas emissions, creation of new local jobs in the Renewable Energy sector, lower energy and utility bills, in lieu of net metering and increase energy grid security.

For Indian Tier I and Tier II cities' local municipalities, a similar plan along with the nationalized banks and other home loan funding agencies could strengthen and pave the way for district level measures, discussed earlier. These could be viewed parallel to SEZs, Special Economic Zones or special assessment districts/ zones, the pre assessment ensuring lower risks for funding agencies.

\section{Pull-Push: The Green Appraisals}

As per the RICS report in case of Affordable housing "Better housing appears to be negatively correlated with centrality of the delivery system and positively correlated with the ability to use land as security for financing." (RICS India, 2010). Meant for affordable housing, the statement remains valid for the MIG sector in India. Looking to add value to their investment, a 'GREEN' valuation/ appraisal for a home owner, leading to a higher market price, can be strong factor for incentivising investment in this MIG and LIG sector, for green upgrade of the existing residential properties.

The present property valuation/ appraisal system in India, exhibits nearly no awareness, recognition or a benchmark/system of green appraisal in India; where rating systems abroad have lent a requirement of distinguishing between the shades of green or rather charting territory within various levels of green, due to code compliance, rating and voluntary adoptions. Darker shades of green implying a higher rating; more intensive and deep measures were adopted in the construction of the house (Sandra K. Adomatis, 2014). Both, a lack of standard rating systems and also due to lack of enough precedence, a system similar or otherwise has not formed yet in India. Advantageously, we can learn from mistakes in prevalent practices abroad and get a working system on the ground, which can be further beta tested, before

\footnotetext{
2 " Comments of Berkeley Law's Center for Law, Energy \& the Environment on the Federal Housing Finance Agency's Proposed Rule re: Enterprise Underwriting Standards and Mortgage Assets Affected by PACE Programs (RIN 2590-AA53)" sent September 12, 2012, Via Electronic Mail, to Mr. Alfred M. Pollard, General Counsel Federal Housing Finance Agency, Eighth Floor, 400 Seventh Street, SW, Washington, DC 20024 (Comments/RIN 2590-AA53)Berkeley Law, University of California, Center for Law, Energy \& the Environment.

3 H.R.2599 -- PACE Assessment Protection Act of 2011 (Introduced in House - IH), HR 2599 IH , 112th CONGRESS 1st Session, H. R. 2599
} 
implementation. Given both increasing built up area, and the stringency we require so as to meet our INDC commitments, a detailed green appraisal system needs to be in place with the view to encourage home owners to invest behind their properties.

A Green Appraisal system, once in place, could be a basis for further measures such as: Easier mortgage availability and Lower interest loans / mortgage rates for green buildings. This could be achieved easily if a fund corpus to act as collateral, is earmarked by banks, governed and controlled by the RBI, especially for this purpose. The fund corpus itself can be generated by taxing mechanisms parallel or from within instruments like the Coal Cess, Swachh Bharat Cess, or from the various funds with the government has charted for 'GREEN-ing" like the Partial Risk Guarantee Fund for Energy Efficiency (PRGFEE), a risk sharing mechanism to provide financial institutions with a partial coverage of risk involved in extending loans for energy efficiency projects, and Venture Capital Fund for Energy Efficiency (VCFEE), a trust fund to provide "last mile" equity capital to energy efficiency companies. (India INDC, 2015)

Incentivising the Distribution Companies - One option could be the system of Clean Energy option that the Discoms could offer the consumers. Like in the US, many companies like green mountain energy, $\mathrm{NV}$, etc are giving the consumer choice of clean energy, as part or complete portion of their consumed units, from within their monthly bills. For the ones willing, the clean energy units are offered at a slight premium. In India, to incentivise the consumer, this portion of the consumer's bill could be further considered for Income Tax exemption. The clean energy option offered by the Discoms can further be encashed by the consumers as clean energy points, a loyalty scheme, which in time can be traded for privileges or discount offers, based on the marketing/tie-ups of the Discoms.

\section{Green CSR}

A big role, in incentivising Green Residential Retrofits can be played by the corporates and their direct employees. The CSR fund, could well be utilised as soft loans given to employees for green home retrofits, at low interest rates. The risk again covered by the government's fund corpus, also aiding the implementation and monitoring to be governed by a system of Third Party Assessors, appointed by the insuring agency. Companies will be truly incentivised when they can further transfer the clean credits from home/ districts/ neighbourhoods to office of their employees. These could amount to and be assessed same as Renewable Energy Certificates for Industries, within the year end energy audits submitted along with the Financial Year Account statements. Converting CSR green retrofits, and the employees who opt for them, into profit centres rather than cost centres.

Transfer of Development Rights - Transfer of Development Rights (TDRs) already in India to address heritage properties, etc could be reinvented in this context with a tripartite arrangement. The First party (the home owner or service consumer) need not put up the capex for retrofits but benefits from reduced tariff; the Second party (municipality/Discom or the Service provider) benefits from reduced subsidy burden; whereas the Third party (a new breed of clean generation companies) could be Demand side aggregators, enjoy development rights to the roof for solar installations and develop district level decentralised waste to energy plants in, above or under public land like parks, roads and canals, or private and semi-private zones like roofs \& compounds.

Enablement is needed in terms of Legality, Insurance cover, Rationalised tariffs, Soft Loans from Banks, Public Institutions/funds as partial guarantors like Partial Risk Guarantee Fund for Energy Efficiency (PRGFEE) and Venture Capital Fund for Energy Efficiency (VCFEE)

\section{Implementation and monitoring}

Route for Incentivizing is lined with Risks. For supplier the risk of investing and not gaining the long- 
term benefit. To hedge this risk, a standard and recognised solution is the Insurance route. The Buyer's risks investment of time, effort and resources behind many suppliers, especially where there might not be a primary supplier, and of being hoodwinked or not getting value for money. These hurdles of implementation and monitoring can be considered while developing a detailed implementation and monitoring plan, and can/ should be decentralised. The few points that might require to be kept in mind.

1. Involve the private sector within the implementation mechanism

2. Third Party Assessors and appraisers to be trained and developed as human resource corpus, with regular and stringent up-gradation of skills, to be monitored centrally, in tandem with the government

3. Risk Insurance to be a critical and pivotal part of the implementation plan, which could be leveraged to assure the quality, through both monitoring and facilitation.

In effect we need to invent viable and out of the box streams of revenue generation by unlocking underutilised spaces like private roof areas for clean energy generation, transfer green credits from home to CSR for employees, killing overheads along a triple bottom line policy encompassing people, profit and planet.

\section{Wrapping Up}

The Indian INDC, presented before the COP 21, talks of demand side management and building conservation measures, both along with the clean energy generation targets. The SMART cities drive, in India aims to retain talent, generate business and meet our overall growth and development aspirations. While it is easier and more economical to bring about Smart and sustainable measures for new brownfield townships, the truth is without uplifting or retrofit of existing built stock we cannot meet our INDC targets.

\section{ACKNOWLEDGEMENTS}

We gratefully acknowledge the help and support of each of the members from SUM@ark, Sustainable Urban Met systems, a green think tank.

\section{REFERENCES}

\section{BEE, B. o. E. E., 2014. DESIGN GUIDELINES FOR ENERGY-EFFICIENT MULTI-STOREY} RESIDENTIAL BUILDINGS, (Composite and Hot-Dry Climates). New Delhi: Bureau of Energy Efficiency, BEE, Ministry of Power, Government of India, 4th Floor, SEWA Bhawan, R K Puram, New Delhi - 110066.

CIPS, C. I. o. P. \&. S., n.d. www.cips.org. [Online] Available at: https://www.cips.org/Documents/Knowledge/Procurement-Topics-and-Skills/5-Strategyand-Policy/Procurement-Policy-Development/POP-Incentivisation.pdf [Accessed 804 2015].

CSE, Center for Science \& Environment, 2014. SUATAINABLE BUILDINGS : A REALITY CHECK, DELHI: s.n.

EAI, E. A. I., n.d. E A I. [Online] Available at: http://www.eai.in/ref/ae/sol/rooftop/power_output [Accessed May 2015].

EESL, Energy Efficiency Services Limited, n.d. Energy Efficiency Services Limited. [Online] Available at: http://www.eeslindia.org/User Panel/UserView.aspx?TypeID=1025 [Accessed 12 2014].

GBPN, 2015. GBPN Global Building Performance Network. [Online] 
Available at: www.gbon.org

[Accessed 6 October 2015].

Governor, O. o. t., 2014. Edmond G Brown Jr., Office of the Governor. [Online]

Available at: https://www.gov.ca.gov/news.php?id=18445

[Accessed 512 2014].

Hofmeister, S., 2014. EDF, Environmental Defence Fund. [Online]

Available at: http://blogs.edf.org/energyexchange/2014/03/19/pace-financing-for-californias-cleanenergy-future-part-1-expanding-the-residential-market/

[Accessed May 2014].

India INDC, C., 2015. INDIA 'S INTENDED NATIONALLY DETERMINED CONTRIBUTION: Working Towards Climate Justice, Paris: UNFCC.

Jones Lang La Salle, JLL, 2012. On Point : Affordable Housing in India, s.1.: s.n.

KPMG, n.d. Decoding Housing for all by 2022, India's commitment to inclusive, sustainable and affordable development, kpmg.com/in: s.n.

MGI, M. G. I., 2010. India's Urban Awakening : Building Inclusive cities, sustaining economic growth, s.l.: s.n.

MoP, B. M. o. P. B. o. E. E., 2007. ECBC, Energy Conservation Building Code 2007. s.1.:s.n.

MoSPI, M. o. S. a. P. I., 2015. Energy Statistics 2015, s.l.: MoSPI.

RICS India, 2010. RICS RESEARCH Making affordable housing work India, s.l.: s.n.

Sandra K. Adomatis, S. L. G. A., 2014. Residential Green Valuation Tools. In: s.l.:s.n., pp. Chapter 2 Challenges of GREEN Valuation.

Satish Kumar, R. K. R. R. S. S. A. W., 2010. Energy Conservation and Commercialisation (ECO-III), California: India, USAID.

The World Bank, 2008. RESIDENTIAL CONSUMPTION OF ELECTRICITY IN INDIA, DOCUMENTATION OF DATA AND METHODOLOGY, Background Paper, India: Strategies for Low Carbon Growth, Draft, s.l.: The World Bank.

US Department of Energy, E. E. a. R. E. D., 2008. Energy Efficiency Trends in Residential and Commercial Buildings, s.l.: s.n. 